\title{
A Study on Preventing Food Wastage in India Using AI
}

\author{
Mr. SAPTADIP SEN, Student, BCA, PES Degree College Bangalore South Campus, India. \\ Ms. AMISHA GUPTA, Student, BCA, PES Degree College Bangalore South Campus, India. \\ Mr. HARSH KUMAR, Student, BCA, PES University, India. \\ Mr. MUKUL PANT, Student, BCA, PES University, India.
}

\begin{abstract}
Exponential Growth of Technology in Asian country has compete a major role altogether spherical development and growth of economy and social development in our country. Asian country has opted for a even handed mixture of autochthone and foreign technology. Purchase of technology is often referred to as "Technology transfer" and it's usually coated by a technology transfer agreement. This work focuses on the key areas of computer science and the way it implements within the future to forestall the waste matter. This write-up nearly identifies the crucial problems or issues related to food \& cash wastage in food. In Asian country there square measure such a big amount of those that aren't obtaining correct food and in an exceedingly same time there square measure some folks with excess food and at the top it goes to the wastage half. Our main intention is distinguishing the issues and giving the mandatory recommendations for resolution the issues encountered. the event of any country is nearly depends on the advancement in developing the technology in numerous fields and cash management. Countries that participate across this age square measure developed additional far more rather more way more than alternative countries as a result of the machine occupies the work more from men. additional advancements in twentieth century in house, aircraft, computers, biotech and knowledge technology square measure boost the developed nations abundant advanced. The new technology with young minds creates an activity each in information and resource utilization. For waste matter calculation and bar we are going to use some powerful artificial intelligence technique, intelligence and technologies.
\end{abstract}

Keywords: Artificial Intelligence, Information, Technology, Money Management, Robotics.

\section{INTRODUCTION}

Due to the development of technology everyday we are learning new concepts and new theory to survive our life . The technology helps us to live our life happily, Since morning to night we are fully dependent of technology same way we are tring to implement technology where it will checks the wastage of something which can be placed into hotel and food industry . which will be helpful to save the wastage of food in a same time many people those who are struggling for food they will have food. If a person is organizing any program by help of this food wastage can be measured . this can also be implemented in hotel hostel and many different places too . it will help a lot to all the food industry .

We all know now a days robot is serving food to table and with accurate delivery ratio of $100 \%$. so we can also implement this so that it will help industry one step ahead . this is one time investment and we required maintenance for this .

\section{AIM OF THIS ANALYSIS}

The main intention of this analysis is to visualize garbage represents whole worldwide paradox! while close to a 3rd of the food created within the world every year is being wasted, at an equivalent time nearly a billion folks area unit unable to hide their daily desires in food. In this respect, this paper offers associate degree innovative associate degreed socially accountable resolution to the garbage challenge by developing an AI garbage management system that keeps track of however kinsmen area unit wasting the food, however will it reduced and what area unit the steps will present itself. Thus, we tend to contemplate discovering new technology within the span of great life and the way it is implies vulnerable, counting on the method technology \& innovative ideas area unit influenced and steered by human selections \& establishments.

\section{MEANING OF AI}

Man-made reasoning (AI) is that the reproduction of human knowledge forms by machines, especially PC frameworks. These procedures typify learning (the 
procurement of information and rules for exploitation the data), thinking (utilizing rules to accomplish rough or unequivocal ends) and self-remedy. explicit utilizations of AI encapsulate talented frameworks, discourse acknowledgment and machine vision. Computer based intelligence is classified as either feeble or solid. Feeble AI, conjointly called thin AI, is partner degree AI framework that is planned and prepared for a chose task. Virtual individual associates, similar to Apple's Siri , territory unit a style of frail AI. Solid AI, conjointly called counterfeit general insight, is partner degree AI framework with summed up human mental component aptitudes. when given with partner degree weird assignment, a strong AI framework is prepared to look out an answer while not human intercession. Since equipment, programming bundle and staffing costs for AI is pricy, a few sellers region unit along with AI components in their standard contributions, moreover as access to registering as a Service stages. Artificial intelligence as a Service licenses individuals and firms to explore different avenues regarding AI for various business capacities and test numerous stages before making a responsibility. elegant $\mathrm{AI}$ cloud contributions typify Amazon Ai administrations, IBM Watson Assistant, Microsoft mental element Services and Google AI administrations. While AI devices blessing a spread of ongoing reasonableness for organizations ,the utilization of registering raises moral inquiries. this can be because of profound learning calculations, that support a few of the first propelled AI instruments, zone unit exclusively as great on the grounds that the information they're given in instructing. because of a character's chooses what information should be utilized for training partner degree AI program, the potential for human predisposition is natural and ought to be checked intently. Some business specialists accept that the term processing is simply excessively firmly joined to chic culture, dispensing the general open to have phantasmagorical feelings of trepidation concerning figuring and mind blowing desires concerning anyway it'll change the geological point and life typically. Specialists and advertisers trust the mark expanded insight, that incorporates an extra nonpartisan implication, can encourage people see that AI can simply improve product and administrations, not supplant the people that utilization them.

\section{How AI will facilitate Fight Food Wastage In India}

Food misfortune and wastage could be an indispensable torment point in a few ventures and throughout the years, the issue is ascending at a quick pace. in accordance with a flexibly, the waste material that is created inside the retail exchange is $\$ 47$ billion (just inside the US). Talking in regards to food wastage in India, the state is confronting significant difficulties inside the offer chain strategy. it's basically the holes, which, whenever tended to , will encourage cut back food wastage inside the country. In any case, with the help of some of the freshest innovation and frameworks, the world's second most thickly settled nation accepts that I will step in to address the matter of food wastage. Associations in India have started to examine the significance of sure innovations that might be wont to decrease food wastage. that is not all, organizations have conjointly started to put resources into things like providing and give chain advancements, the square chain, AI, data watching, stockpiling and bundling arrangements.

\section{Intelligent and Innovative System Combating Food Wastage}

Computerized reasoning, Machine Learning, and data Science throughout the years have developed to get one thing unbelievable, supporting people in making the least difficult decisions. Today, these insightful frameworks have denoted their essence in numerous elective businesses, and in this way the food exchange is one in everything about. For instance, if investigate a food showcase, there's huge amounts of food things that visit squander day by day, and this is regularly generally because of a dreadful interest forecast. during this circumstance, AI will assume a huge job and cut back the quantity of food wastage. With the help of past data on what amount food goes to squander, what amount an item gets the chance to sell, AI will assemble an improved interest forecast. it may encourage food advertise house proprietors to arrange things at partner sufficient level - no more or not less. Another occurrence is that the organization among Hitachi and a medical clinic. in order to watch trash, the Japanese organization Hitachi accomplices with a medical clinic to utilize AI. Emergency clinics ceaselessly witness a significant amount of food wastage because of numerous reasons. one in all the clarifications is once patients aren't take-up — during this case, it's not seeing practically about around as respects to near worried close to regarding the matter of in regards to concerning with respect to trash anyway also about wellbeing suggestions. The origination is to mount a camera on the cable car that gathers plate. The camera would take film of the extras, which may later be analyzed by the Hitachi's profound learning calculations. In this way, with the help of the once supper examination, Hitachi would have the option to perceive designs inside the extras that people in any case couldn't see. Talk in concerning utilizing a camera to watch food, MIT joins a food cam. It works during an extremely clear and natural way. Assume there's some extra eatable food, you just should press the food cam catch and it shares the picture of food on channels like Twitter, Slack and a posting. When it's shared, individuals that desire to eat will return and get it. clear origination all things considered one in all the first successful. Furthermore, to the shock, it had been unbelievable in 1999, preceding Facebook, Gmail, and so on was presented. Based enter the America, Agshift is another pleasant case of an enterprise that is battling food wastage. the corporate has created partner independent food investigation framework that utilizes profound learning. 
The models will break down the deformities inside the example pictures and foresee the general nature of the example. On the off chance that we look at the Bharat circumstance, the food wastage is commonly because of a poor give chain. Thusly, it's gotten basic for Indian food partnerships to receive innovation at each phase of the arrangement chain. The reefer-compartment is one such advancement that is partaking in a principle job to address the trouble of food wastage. The instrumentation isn't exclusively serving to save the food later for longer than a month anyway also serving to adjust agribusiness makers to sufficiently send all product across geologies. Clever and inventive frameworks will while not an uncertainty improve planning inside the give chain. and furthermore the Indian Govt. is taking activities in building framework for the food exchange and battle food wastage.

\section{SAP Use Case}

So as to unwind the agony purpose of food wastage, SAP worked with Costco to make partner insightful framework to help the America shipper to stack long stretches of business data and outer parameters like advancement, coupons and so on that Costco provided for its clients. misuse the stacked data the corporate had the option to manufacture a model that took in this and had the option to foresee what amount food must be solid on self on a day by day to satisfy the business target speedily. This not exclusively encouraged Costco to scale its business anyway furthermore help in address the food wastage drawback. That isn't all, the framework had the option to screen the deals and furthermore the in progress wastage and circle it back to higher its expectation.

\section{Outlook}

It isn't at all even a tiny bit in the smallest degree in partner regard a misrepresentation after we state that food wastage is one in all the most significant issues that the mankind is seeing these days. Governments and partnerships over the globe have taken numerous activities to battle this issue, be that as it may, is anything but a basic undertaking. Innovation is also getting a charge out of in its part inside the fight to relieve food wastage, anyway till and except if we tend to don't act, this issue won't is settled absolutely.

\section{What IS Waste Management?}

The term 'Waste Management' together recommends that the administration of waste from its birthplace to a definitive phase of removal. In this manner, together single unit, it envelops directly from the social affair, removal, reusing, to that the procedures of perception and guideline, severally have a place with, close by the lawful structures that adjust the commonness of waste administration. "Waste management or waste disposal area unit all the activities and actions needed to manage waste from its origin to its final disposal. This includes amongst alternative things assortment, transport, treatment and disposal of waste along with observation and regulation. It additionally encompasses the legal and regulative framework that relates to waste management encompassing steering on usage."

\section{Points of interest or edges of Waste Management:}

As referenced on, squander the executives includes the gettogether and removal of each dangerous and non-risky squanders from all the areas of society. we tend to will presently look personally the favorable circumstances the edges of waste administration or advantages of right electric pig.

1. is follow is exceptionally worthwhile: The Journal of Waste administration says that the incomes produced by the waste administration would high by $\$ 60$ million by 2018 . $\mathrm{Be}$ that as it may, there region unit exclusively various individuals that genuinely consider this partner exchange into various sides of waste administration like utilization and reusing, and procure the advantages.Now a few organizations zone unit attempting forward to partner themselves with this exchange and territory unit arranged for an all-inclusive term speculation

2. Keeps the environmental factors perfect and new: Perhaps, the best favorable position of waste administration is keeping the environmental factors new and slick. These waste removal units conjointly make the people go illness free as all the resultant squanders territory unit appropriately arranged and brought care of. More scope of waste removal units might be put on the whole the level 1 and level 2 urban communities all together that the waste removal strategy might be prepared up. conjointly a degree warrant our idea here is that this preferred position might be thought about on condition that concentrated and right wellbeing estimates region unit implemented close by right waste removal procedures. There is no utilization in just actualizing a silly strategy that, if no utilization to each the people and along these lines the setting. this can be the best impacts of right waste removal.

3. Saves the world and monitors vitality: This trait of waste administration incorporates explicitly the use aspect. As use of waste aides in decreasing the downsizing of trees. This cutting of trees is basically completed the get together of paper. By abuse this approach, we can utilize reused waste to frame quality papers as opposed to anticipating trees. Likewise, use needs exclusively a base amount of vitality for usage and complete procedure. The resultant item we will in general get might be a sustainable flexibly of vitality and is eco-accommodating

4.Decreases natural contamination: As clarified on, squander the board whenever tired a right way not exclusively dispenses with the surrounding waste anyway conjointly can downsize the force of the ozone depleting substances like alkane, monoxide that is produced from the squanders aggregated. The profundity of the current 
landfills and burning will be limited, in this manner downsizing the unsafe elements that affect the setting.

5.Waste administration can assist you with gaining cash: have aforementioned on top of is completely true? affirmative, waste management earns you some additional used each month. Actually, there area unit several firms which is able to pay you for your waste. Right from previous and used bottles to tin cans and wastes, all types of wastes area unit collected and paid. These wastes area unit then segregated in line with the extent of pollution they cause to the setting and these wastes area unit recycled consequently for numerous functions. There also are crash courses obtainable which is able to aid you to utilize your trash. Above all, by following this methodology, you'll produce associate awareness to your fellow individuals by earning cash that may be a win-win conception

\section{Creates employment:}

Again, this facet too is unbelievable for you... right? you will even raise why this can be possible? however all told the aspects of waste management, an enormous quantity of labor is required. Right from the gathering to the ultimate step of segregation, each part wants personnel and ultimately an outsized range of employment opportunities get unfolded. This claim is obvious from the labor statistics provided by the federal government, in line with that around three. 1 million new jobs area unit created because of the waste management issue.

\section{Disadvantages of Waste Management:}

We have currently seen the deserves of waste management thoroughly. allow us to currently have a glance at the disadvantages conjointly.

1. the method isn't forever cost-effective: Yes, though' it's going to pay to the contributors, the reality is that this method wants tons of cash, time and land to line up a plant and run. because the quantity of waste that's being contributed to the waste material unit will increase, therefore area unit the quantity of plants that method these resources. fitting an enormous works clearly wants tons of cash, and this management can begin winning yields solely within the end of the day. Hence, this can be not seen as a short remunerative investment. whereas marketing additional and additional garbage's within the landfills cause solely $\$ 50$ per ton, utilization them within the correct manner can cause $\$ 150$ per ton, that is strictly triple the price and therefore several of the businesses tend to modify over to the lowland methodology itself.

2. The resultant product features a short life: This is conjointly true since the ensuing recycled product can not be expected to own a sturdy quality. because the product itself has its origin from the remains of the opposite trashed waste product and loads of part used ones. The recycled product, though, is eco-friendly is predicted to own a shorter era than the meant original one.

3. The sites area unit typically dangerous: As the waste management sites embody the landfills to utilization units beneath its aegis, these sites area unit extremely vulnerable to plant life and microorganism growth thereby resulting in numerous diseases. Even the scrap formation are going to be accelerated by such microorganism growth, that makes it all unsafe for the employees WHO work there. It conjointly causes widespread pollution and releases harmful chemicals. These chemicals, once mixed with drinkable or the other expendable item create a high quantity of danger to human health.

4. The practices don't seem to be done uniformly: Still, an outsized scale of those waste management practices area unit done solely as a tiny low scale method and is usually confined to residential homes, schools, and schools and isn't practiced in a very uniform manner in massive industries and conglomerates. it's not even practiced globally, because the international level consists of edge oil spills, ocean disposals and decreasing the tree felling.

5. Waste management will cause additional problems: Though waste management creates employment, it solely has the flexibility to provide low-quality jobs. These jobs embody right from sorting the rubbish collector to the intensive and heavy jobs that area unit required within the factories and retailers. Daily basis assortment of garbage's can create the streets look unpleasant and insanitary going away excess scrap on the streets to rot up. Even once the fortunate completion of the ultimate stage, several chemical stews are going to be left behind that has to be properly and utterly disposed, otherwise, they'll conjointly create a threat to the setting that makes the final word purpose of waste management go redundant. Also, within the area unites wherever these management units are gift, it's detected that the groundwater gets affected. So, it too causes a considerable extent of pollution and land pollution.

\section{CONCLUSION}

Food waste in sustenance restaurants could be a serious issue that contributes to social, environmental, and economic issues. It ends up in higher rates of food insecurity, particularly among necessitous families, causes region pollution, and leads to several bucks wasted on inputs. To combat this issue, we have a tendency to planned a concept to encourage sustenance chains to present excess food, utilize perishable provides, and recycle. we have a tendency to found that the sole thanks to get this initiative going is to lobby the govt. to pass legislation that encourages the said behaviors. In doing thus, it'll offer economic incentive for business homeowners, and social cause for community members. Of course, a concept like this is often costly. But, with correct funding, it will be done. once it's complete, we have a tendency to hope to 
assess the progress of the arrange by referring back to our recycle committee, the USRAC, and determinant that firms have really recycled. Therefore, by shifting answerableness on businesses, we have a tendency to hope to finish the difficulty of sustenance waste and save lives.

\section{REFERENCE}

1. https://searchenterpriseai.techtarget.com/AIArtificial-Intelligence

2. https://sites.google.com/site/foodwasteatmcdonald s/

3. Wikipedia.

4. Quora .

5. https://hackernoon.com/why-we-are-automatingfood-waste-management-with-ai-9b1kp28qk

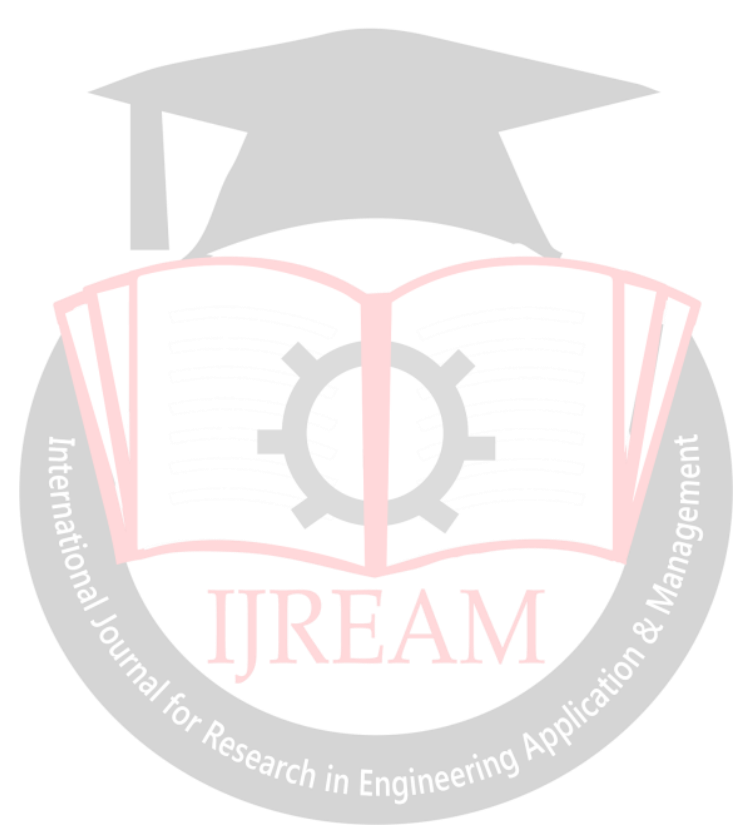

